\title{
O conceito de substância e seus desdobramentos: uma visão geral da metafísica de Leibniz
}

The concept of substance and its developments: an overview of Leibniz's metaphysics

\section{Victor Frohlich}

Universidade de São Paulo 
RESUMO: Pretende-se investigar os elementos centrais do conceito de substância no pensamento de Gottfried Wilhelm Leibniz, tomando a complexidade de tal conceito e suas diversas formulações como prerrogativa para analisar os diversos textos do autor, observando os caminhos argumentativos trilhados nessas obras e o desenvolvimento de outros de seus temas centrais e conceitos chaves - notavelmente, a harmonia preestabelecida e o papel de Deus em sua cosmologia. Parte-se, também, da premissa de que a heterogeneidade e a polissemia conceitual do autor podem ser tomadas como qualidades de um sistema de particular riqueza filosófica, que não se apresenta em um único texto dito "canônico" do autor.

PALAVRAS-CHAVE: substância; Mônada; metafísica; lógica; harmonia.

ABSTRACT: We intend to investigate the central elements of the concept of substance in Gottfried Wilhelm Leibniz's thought, taking the complexity of such concept and its multiple formulations as a prerogative to analyze several texts from the author, minding the undertaken argumentative paths on those works and the development of other core themes and key concepts - notably, the pre-established harmony and the role of God in his cosmology. We also move from the premiss that the author's heterogeneity and conceptual polissemy can be taken as qualities of a particularly rich system of philosophy, that does not presents itself in a single, said "canonical", text from the author.

KEYWORDS: substance; Monad; metaphysics; logic; harmony. 
Como entrar no pensamento de Leibniz? Como mergulhar em seu vasto conjunto de obras, ensaios e opúsculos, com diversos trabalhos igualmente ricos, sem, contudo, nenhum que definitivamente se destaque como detentor de uma exposição completa, sistemática e, digamos, "canônica" de seu pensamento? Apesar de quase sempre a respeito da existência de Deus, do mundo e dos princípios gerais - físicos e metafísicos - que imperam sobre a Criação, como lidar com esses textos que abordam uma miríade de temas recorrentes, não obstante, de maneira por vezes conflitante e com uma terminologia que não poderíamos classificar, precisamente, como coesa? Destarte, nos encontramos em uma complicada situação quando decidimos dar nossos primeiros passos na teia conceitual do filósofo em questão. Uma abordagem meramente cronológica, partindo de seu Discurso da Metafísica, de I686, em direção aos seus últimos escritos, a saber, a Monadologia e os Princípios da Natureza e da Graça fundados na Razão, de I7I4, já parece pressupor uma abordagem teleológica e progressiva, opção que, além de engessada por privilegiar uma suposta "maturidade" final, aparenta ser pouco condizente com o pensamento do autor, que nunca chega a desenvolver um sistema plenamente formado, o que não nos autoriza, por conseguinte, a tomar essas "exposições iniciais" como meros

I Que não deixam de ser textos de maturidade, inclusive. Leibniz, é sabido, começou seus estudos muito antes da elaboração de seu Discurso, estudando nas décadas que precederam esta obra uma 
esboços de juventude. Se invertemos a lógica e procuramos - para usar a expressão de Victor Goldschmidt - uma abordagem rigorosamente dogmática destes primeiros textos sobre a metafísica e as substâncias, como o supracitado Discurso e o Sistema novo da natureza e da comunicação das substâncias, de 1695 , dentre outros, corremos o risco de ignorar as mudanças e retomadas temáticas que o autor efetuou nas décadas que se seguiram.

Se procuramos, então, guiar-nos por uma análise temática de seu pensamento, defrontamos com dificuldades similares: devemos partir das substâncias e das criaturas para enfim observarmos os princípios universais da metafísica e de Deus? Ou, então, começamos nossas considerações a partir de Deus, da harmonia preestabelecida por Este e dos princípios lógicos que Seu Entendimento aplica na Criação e na contingência do mundo? Mesmo o autor não parecia muito certo de qual seria o melhor caminho: parte da riqueza de seus escritos está na multiplicidade de abordagens argumentativas que adota, efetuando ascensões e declínios entre o plano físico e o metafísico. Para citar apenas dois casos: no Discurso, parte de Deus para as substâncias individuais, passando pelas leis mecânicas e retornando, pela hierarquia das substâncias, à Cidade de Deus; no Sistema novo, parte de uma exposição autobiográfica em que critica os atomistas, restaura as formas substanciais e segue em ascenso até a divindade e seu reino - para concluir, nos últimos parágrafos, com um breve retorno à matéria e suas leis.

Estes parágrafos iniciais não têm outro intuito além de expor (i) um conjunto de perplexidades que envolvem o pensamento de Gottfried

variedade de temas e disciplinas, desde o direito e as ciências jurídicas (nas quais se graduou, inclusive) até as ciências naturais (que o levaram, por exemplo, à invenção do cálculo infinitesimal). Para uma breve e sintética biografia do autor, recomendo a "Vida e Obra" que serve de introdução aos seus Novos ensaios sobre o entendimento humano, lançado pela Nova Cultural (LEIBNIZ, I996, p. 5-I2). 
Wilhelm Leibniz, um dos principais filósofos racionalistas do século XVII; (ii) que, obviamente, qualquer porta de entrada que usemos em seu sistema é, por si só, uma escolha filosófica; e (iii), sem maiores delongas, apresentar a premissa inicial que conduzirá as reflexões das próximas páginas: seu pensamento pode apenas ser compreendido se tomado em sua totalidade, e pode ser tomado, conforme se pretende demonstrar, como um sistema filosófico de extrema riqueza, sendo sua argumentação por vezes fugidia - quando tomada no conjunto de suas obras -, não um sinal de confusão ou falta de clareza expositiva, mas justamente de pluralidade metodológica e de uma harmonia lógica que não se pode restringir a uma linearidade estanque. Dito isso, partimos, então, de uma passagem que parece nos permitir uma visão geral (e, aqui, ainda superficial) do pensamento leibniziano: no §XIX de seu Discurso, reafırma sua opção de aliar as causas finais - divinas, metafísicas e morais - à compreensão das causas eficientes - materiais, físicas e necessárias - no seio de uma crítica ao mecanicismo moderno; retomando, assim, o tema da benevolência suprema de Deus, o autor afirma:

Posso bem admitir que estamos sujeitos a nos excedermos quando pretendemos determinar os fins ou resoluções de Deus, mas tal apenas acontece quando pretendemos limitá-los a algum desígnio particular, acreditando que ele só teve em vista uma única coisa, ao passo que Deus tem em vista tudo, ao mesmo tempo. Assim acontece quando cremos não ter Deus feito o mundo senão para nós. Grande abuso é este, embora seja muito verdadeiro tê-lo feito inteiramente para nós, e nada haver no universo que não nos diga respeito e não se acomode, ainda, às considerações que tem Deus a nosso propósito (...). (2004, p. 4I, grifo nosso)

Podemos estabelecer alguns pontos com essa passagem. Sobretudo, é possível notar a centralidade do conceito de substância, implícito na passa- 
gem grifada. Assim, nosso objetivo central será o de tentar reter os principais elementos deste conceito no pensamento de Leibniz - tarefa particularmente complexa, uma vez que, como veremos, tal conceito é justamente um dos que mais se modifica em sua filosofia. Dada tal dificuldade, acreditamos que não é possível compreender o conceito de substância e suas variações em Leibniz sem uma investigação de seu sistema metafísico em sentido lato; ou seja, faz-se necessário compreender o conceito de substância no interior do pensamento leibniziano, isto é, em conjunto com outros temas marcantes, para que então seja possível efetuar uma análise detida sobre este conceito e suas diferentes abordagens no corpus leibniziano; caso contrário, corremos o risco de tomar um conceito ou desígnio particular como centro absoluto de seu sistema, o que não parece ser o caso.

\section{DEUS E A HARMONIA LÓGICA}

Faz-se necessário, em outras palavras, efetuar um percurso por vários textos de Leibniz e observar diversos dos seus princípios metafísicos, para então compreender a centralidade da substância para seu pensamento e a conexão destas com a harmonia da Criação. Iniciaremos nosso percurso, então, pelas definições mais amplas do pensamento metafísico do autor, notavelmente sobre Deus e os princípios lógicos do mundo, com o intuito de compreender seus fundamentos, evitando, assim, uma análise demasiado específica de seus conceitos.

Dizíamos anteriormente que uma das dificuldades mais marcantes dos estudos em Leibniz é a variedade de textos que abordam os mesmos temas com algumas sutilezas particulares em cada caso. Não obstante, encontramos em seu texto Da origem primeira das coisas, de I697, uma das exposições mais frontais a respeito de Deus, definido como a "razão última extramundana das coisas" (LEIBNIZ, I974, p. 393), e da distinção entre o 
plano físico e o plano metafísico. A oposição entre estes dois planos fica nítida quando, após algumas notas iniciais sobre Deus e sobre a impossibilidade de estabelecer a razão primeira da existência a partir do plano dos objetos condicionados, Leibniz passa a enfatizar a importância de

\begin{abstract}
(...) chegar-se da necessidade física, ou hipotética, que determina as coisas posteriores do mundo pelas anteriores, a alguma coisa que seja de necessidade absoluta, ou metafísica, da qual não se possa dar a razão. Ora, o mundo presente é necessário física ou hipoteticamente, mas não absoluta ou metafisicamente. (LEIBNIZ, 1974, p. 394)
\end{abstract}

Estes dois planos de necessidade, todavia, têm vastas diferenças: entre aquilo que é "metafisicamente necessário, de modo que o contrário implique contradição ou absurdo lógico [e aquilo que é] necessário fisicamente, ou determinado, de modo que o contrário implica imperfeição ou absurdo moral" (LEIBNIZ, 1974, p. 395), existe uma fronteira sem a qual se cai inexoravelmente em um necessitarismo absoluto, o que extinguiria qualquer possibilidade de liberdade, tanto para Deus quanto para as criaturas. Mais tarde abordaremos com detalhe a questão da liberdade; por ora, é preciso atentar-se aos princípios que fundamentam a distinção acima, e que já se ensaiam na citação escolhida. Primeiramente, é a partir desta oposição e da afirmação de que Deus é o único ser "cuja essência pertence a existência" (LEIBNIZ, 1974, p. 394) que podemos entender um dos princípios fundamentais da existência, a saber, que tudo que é possível - ou seja, que não implica contradição em si mesmo - tende "com igual direito à existência conforme a quantidade de essência ou realidade, ou conforme grau de perfeição que envolvem" (LEIBNIZ, 1974, p. 394), o que nos leva a compreender que a realidade é governada por "um princípio de orientação tirado do máximo ou o mínimo, de modo que se produza o máximo efeito com o mínimo de gasto, por assim dizer" (LEIBNIZ, I974, p. 394), ou 
melhor, que "na produção das coisas se tenha exercido certa matemática divina, ou mecanismo metafísico" (LEIBNIZ, I974, p. 395). Mas as afirmações supracitadas parecem pressupor ainda outros princípios, como a razão suficiente ou completa para a existência da qual Leibniz fala, sem grandes detalhes, no §i deste texto, e que não abordamos ainda. Como isso se dá?

Uma das primeiras características que se nota no pensamento leibniziano, e que pudemos conferir na definição de necessidade metafísica acima, é o rigor com que a realidade é estabelecida a partir do entendimento de Deus e dos princípios gerais que ele contém. Tais princípios não podem, é verdade, ser totalmente apreciados por seres finitos e imperfeitos; mas certas leis e propriedades lógicas podem ser observadas, com algum cuidado e reflexão, pelo espírito humano, que pode então observar a perfeição da criação divina e da ordem e harmonia estabelecidas por Este a partir de princípios universais como o da não-contradição e da razão suficiente. Como diz Franklin Leopoldo e Silva, em rico comentário sobre Leibniz,

\begin{abstract}
(...) existe (...) uma instância de inteligibilidade fundamental que justifica o projeto de racionalismo integral como característica do pensamento de Leibniz: tal instância deve ser concebida como anterior a todo e qualquer conteúdo proposicional, seja ele de caráter físico ou metafísico. (...) Esta instância, para Leibniz, é a Lógica. (2006, p. 48)
\end{abstract}

Entender o raciocínio que Leibniz engendra em seus trabalhos é, talvez, uma tarefa impossível se não se leva em conta o rigor lógico neles presente, e estes princípios fundamentais, acessíveis por meio da Metafísica mas, justamente por seu estatuto divino, anteriores mesmo a esta. Este aspecto universal fica talvez mais nítido nos Princípios da Natureza e da Graça, quando o autor, após discutir sobre as mônadas e as criaturas, afirma o seguinte: 
Até aqui falamos como simples físicos; agora devemos elevar-nos à metafísica, valendo-nos do grande princípio, pouco empregado usualmente, que afirma que nada se faz sem razão suficiente, isto é, que nada ocorre sem que seja possível àquele que conheça suficientemente as coisas dar uma razão que baste para determinar por que é assim e não de outro modo. (2004, p. ${ }^{58} 8$, grifo do autor)

Este grande princípio, aplicado por este Deus que têm "a potência, o conhecimento e a vontade perfeitos" (LEIBNIZ, 2004, p. I58), culmina enfim na afirmação de que, "ao produzir o universo, Ele elegeu o melhor Plano possível, no qual existisse a maior variedade possível associada à maior ordem possível" (LEIBNIZ, 2004, p. I59). Assim, as afirmações de seu texto de 1697 ficam mais inteligíveis, e o Mecanismo Metafísico em ação prova ser um conjunto de postulados lógicos e juízos morais invariavelmente perfeitos de um ser, por definição, de soberana perfeição. Não por acaso, a partir dos princípios de não-contradição e razão suficiente, os dois grandes princípios sobre os quais o raciocínio humano está fundamentado², nos fica evidente que Deus não poderia ter feito uma obra menos perfeita ${ }^{3}$, sendo não apenas pecaminoso, mas ilógico afirmar que se poderia atingir maior perfeição na Criação. "Pois como todos os possíveis pretendem à existência no entendimento de Deus na proporção de suas perfeições, o resultado de todas essas pretensões deve ser o Mundo Atual o mais perfeito possível". (LEIBNIZ, 2004, p. I59)

São estes princípios lógicos, em suma, que fundamentam a existência de Deus e as provas a priori e a posteriori d'Ele, o que é demonstrado por Leibniz em sua Monadologia; depois de estabelecer os princípios lógicos do intelecto humano, e de distinguir entre as verdades de raciocínio - neces-

2 Esta é a definição que aparece nos $\$ \S 3^{\mathrm{I}-32}$ da Monadologia.

3 É esta, também, a discussão que abre o Discurso da Metafísica, §§I-III. 
sárias e cujo oposto é impossível - e de fato - contingentes e cujo oposto é possível -, o autor estabelece, inicialmente, a necessidade da existência de um Deus suficiente a partir da ordem das criaturas e da contingência (\$§33-40), para, então, em argumento muito similar ao exposto anteriormente em Da origem primeira das $\operatorname{coisas}^{4}$, provar a existência necessária de Deus a partir de sua essência perfeita $(\S \S 4 \mathrm{I}-45)$. Assim, parecem demonstrados alguns dos pressupostos centrais do pensamento leibniziano, a partir dos quais podemos entender com mais clareza a origem das criaturas e dos espíritos racionais que habitam o mundo. Afinal, uma vez que "só Deus é a unidade primitiva ou a substância simples originária, da qual todas as Mônadas criadas ou derivativas são produções" (LEIBNIZ, 2004, p. I39), é possível então, tendo em mente estes princípios metafísicos, começar a compreender a "harmonia preestabelecida entre todas as substâncias, pois todas elas são representações de um mesmo universo" (LEIBNIZ, 2004, p. I46, grifo do autor).

\section{AS SUBSTÂNCIAS}

Passamos, então, para uma nova questão, central neste trabalho: o que é a substância em Leibniz? A dificuldade terminológica atinge, aqui, seu ponto máximo. Entre i686 e i7i4, o autor fez uso de uma genuína miríade de termos e conceitos para definir e hierarquizar as substâncias ou mônadas que compõem a realidade e não se confundem, contudo, com a matéria em

4 Vale notar como os movimentos em ambos os textos são similares: também temos, no texto de I697, apesar de não serem apresentadas explicitamente desta forma, uma prova a posteriori seguida de uma confirmação a priori de Deus; isto é, primeiro, a constatação da unidade extramundana ou fonte dos detalhes da razão suficiente e universal, e, depois, a prova definitiva deste Ser necessário, perfeito e supremo, o único cuja essência é a existência e que realiza a existência do melhor possível, ou seja, daquilo que não é estritamente necessário. Infelizmente, como esta questão não é o foco de nossas considerações, não convém que nos alonguemos sobre ela aqui. 
si5. O problema, todavia, não pode ser reduzido apenas a uma mera dificuldade de termos, que poderiam então ser catalogados e dispostos como que em um glossário. Por vezes, um mesmo termo tem significados diferentes; em outras, seu sentido permanece mas novas definições complementares são adicionadas. Uma solução definitiva aos dilemas que circundam estas definições no pensamento de Leibniz, evidentemente, não é o objetivo deste trabalho e de seu diminuto escopo; não obstante, tentaremos fazer uma análise dos conceitos mais marcantes e constantes das substâncias no decorrer das obras do autor.

Falávamos do plano da metafísica, de Deus; voltemos agora nossos olhos ao plano físico, das criaturas. Contudo, parece-nos produtivo começar esta exposição dando continuidade aos princípios que vimos anteriormente; afinal, é justamente porque existe uma ordem perfeita, contemplável pela razão, que a perfeita beleza da criação se desvela. Como diz o autor em seu Discurso da Metafísica, "Deus escolheu (...) o mais perfeito [dos mundos], quer dizer, ao mesmo tempo o mais simples em hipóteses e o mais rico em fenômenos" (LEIBNIZ, 2004, p. I3), não por mera necessidade física e metafísica - outros mundos poderiam existir, e seriam sem dúvida igualmente bem ordenados pelo entendimento divino -, "mas também moralmente falando" (LEIBNIZ, 2004, p. 3), de acordo com seu desígnio e visando sempre à felicidade das criaturas e, em especial, dos espíritos racionais; e, evidentemente, da harmonia à qual estes entes, simultaneamente, pertencem e exprimem.

Para entender como isso se dá, e o que é esta hierarquia que aqui se ensaia, devemos procurar pela primeira definição de substância individual que Leibniz propõe. Esta aparece no §VIII de sua obra, como um sujeito

5 Distinção que aparece claramente em seu Sistema novo, §ıI. 
que comporta um número ilimitado de predicados e que não é, por sua vez, predicado de nenhum outro sujeito; ademais, estes predicados estarão contidos expressa ou virtualmente na substância, i. e., atualmente efetivados em sua existência ou inscritos em sua essência, mas não ainda efetivados. Assim deve ser a natureza da substância, ou seja, "uma noção tão perfeita que seja suficiente para compreender e fazer deduzir de si todos os predicados do sujeito a que se atribui esta noção" (LEIBNIZ, 2004, p. r6); o que acarreta, por sua vez, à conclusão de que uma substância individual guarda "vestígios de tudo quanto the sucedeu, marcas de tudo o que lhe sucederá e, ainda, rastros de tudo quanto se passa no universo, embora só a Deus caiba reconhecê-los todos" (LEIBNIZ, 2004, p. I7).

Esta formulação lógica a respeito das substâncias individuais leva Leibniz a restabelecer as formas substanciais da escolástica. Tal resgate conceitual dá continuidade aos pressupostos estabelecidos acima, que levam o autor à conclusão de "não consistir apenas na extensão, isto é, na grandeza, figura e movimento, toda a natureza do corpo, mas ser preciso necessariamente reconhecer nele algo relacionado com as almas e que vulgarmente se denomina forma substancial" (LEIBNIZ, 2004, p. 23). Apesar das diferenças entre "as almas e as formas substanciais dos outros corpos [e das] almas inteligentes" (LEIBNIZ, 2004, p. 23), que veremos com mais detalhe em breve, podemos compreender como o pensamento leibniziano toma distância do pensamento atomista moderno, que postulava átomos indivisíveis da matéria, ao estabelecer um conceito de substância formal que dá coesão a um mundo formado de matéria infinitamente divisível.

Encontramos, então, as bases metafísicas das formas substanciais, mas tal conceito parece ficar ainda mais nítido em seu Sistema novo, quando, após descrever em tom autobiográfico sua passagem pelo pensamento atomista, o autor revela a insuficiência das explicações meramente mecâ- 
nicas a respeito da res extensa e a subsequente necessidade de "empregar ainda a noção de força, a qual é plenamente inteligível, ainda que pertença à esfera da metafísica” (LEIBNIZ, 2002, p. I6). Essas considerações fundamentam, deste modo, a busca pelos "princípios da verdadeira unidade" (LEIBNIZ, 2002, p. I6, grifo do autor), que não podem ser verificados em um mundo que se encontra, materialmente, em estado de passividade e infinita divisibilidade, e, sim, nos verdadeiros "átomos de substância que devem envolver algo de formal ou de ativo para fazer um ser completo" (LEIBNIZ, 2002, p. I7). Esta partícula metafísica indivisível seria, justamente, a forma substancial, cujas características ficam ainda mais nítidas em uma passagem mais à frente, no §II do mesmo texto:

Há somente átomos de substância, quer dizer, unidades reais e absolutamente desprovidas de partes e que são as fontes das ações, os primeiros princípios absolutos da composição das coisas, e como que os últimos elementos da análise das coisas substanciais. Eles podem ser chamados de pontos metafísicos: eles possuem algo de vital e uma espécie de percepção, e sendo os pontos matemáticos seus pontos de vista para exprimir o universo. (2002, p. 24, grifo do autor)

Ao mesmo tempo, os princípios que compõem a realidade e os objetos últimos da análise do mundo, isto é, os mais profundos e absolutos entes que constituem a realidade, as substâncias começam a tomar forma no sistema leibniziano - ou melhor, obviamente, na exposição que propomos. Mas é preciso que nos retenhamos agora às diferenças entre os diversos tipos de substâncias, isto é, entre as almas brutas ou formas ordinárias que preenchem a matéria (LEIBNIZ, 2002, p. I9) e os espíritos ou almas racionais, dotados de uma unidade intelectual que conhecemos vulgarmente como eu (LEIBNIZ, 2002, p. 23). Ou seja, é preciso que nos detenhamos sobre os princípios que imperam sobre todas as substâncias 
indistintamente, e que observemos as diferenças entre as substâncias irracionais que constituem toda a matéria do mundo e aquelas dotadas de razão e de um corpo material sob seu controle. É assim, me parece, o melhor caminho para debruçarmo-nos sobre o advento do conceito de Mônada, nos últimos trabalhos de Leibniz, que nos permitirá também compreender melhor a hierarquia substancial que o autor propõe. Assim, na Monadologia, o autor começa por defini-las como "substância simples, que entra nos compostos; (...) os verdadeiros Átomos da Natureza e, em suma, os Elementos das coisas" (LEIBNIZ, 2004, p. I3I), o que nos leva a entender as mônadas como algo, a princípio, pouco diferente ou mesmo idêntico às substâncias simples. É com algum espanto, dessa forma, que tomamos a afirmação pouco a frente, a respeito da independência das mônadas, de que "nem substância nem acidente podem, de fora, entrar em uma Mônada" (LEIBNIZ, 2004, p. I32). Estaria o autor se referindo apenas à incorruptibilidade ${ }^{6}$ da Mônada em relação às outras mônadas e substâncias, ou seria este novo conceito uma maneira de descrever algo que subjaz às próprias substâncias?

Um pouco das duas coisas, talvez; mas, a rigor, nenhuma das duas. Ao menos é o que me parece evidenciar-se algumas páginas à frente. As mônadas, de fato, trazem características muito similares às substâncias individuais dos textos anteriores: são indestrutíveis, independentes, únicas, dotadas de percepção e apetição (LEIBNIZ, 2004, p. I33), e regidas por "um princípio interno, já que uma causa externa não poderia influir em seu interior" (LEIBNIZ, 2004, p. I32, grifo do autor); por conseguinte, "poder-se-iam chamar Enteléquias todas as substâncias simples ou Mônadas criadas" (LEIBNIZ, 2004, p. I34, grifo do autor). Não obstante, diz então o autor:

6 Qualidade essencial das substâncias, à qual Leibniz faz referência em diversos momentos - como no Discurso, §IX; no Sistema novo, §4; na Monadologia, §§6, 7; e nos Princípios da Natureza e da Graça, §2. 
Se quisermos chamar de Alma tudo o que tem percepções e apetites no sentido geral que acabo de explicar, todas as substâncias simples ou Mônadas criadas poderiam ser chamadas de Almas; mas, como o sentimento é algo mais que uma simples percepção, admito que o nome geral de Mônadas e de Enteléquias baste para as substâncias simples que só tenham percepção; e que se chame de almas só aquelas cuja percepção é mais distinta e acompanhada de memória. (2004, p. 134)

Ou seja: existe uma distinção clara entre as mônadas ou enteléquias presentes na matéria e as mônadas dotadas de memória - que podem também ser distinguidas entre aquelas que se valem apenas da memória, isto é, os animais, e aquelas que se valem também da razão e "do conhecimento das verdades necessárias e eternas [, que são] o que se chama de alma racional ou espírito" (LEIBNIZ, 2004, p. 136). Outra passagem iluminadora a este respeito nos dá, também, mais detalhes acerca da união entre esta alma e o corpo que ela possui, um dos problemas centrais ao racionalismo, e dos motivos que levam Leibniz a criticar com tanta veemência a concepção atomista. Um corpo orgânico sempre pertencerá a uma mônada, seja mera enteléquia ou alma, que forma, sob o domínio dessa mônada, uma máquina natural e divina; e o que torna essas máquinas tão especiais - e propriamente divinas, perfeitas e distintas das máquinas humanas - é a infinidade de partes que a compõem, e que demonstram a sabedoria por detrás da ordem harmônica - física e metafísica, mecânica e moral - de Deus:

E o Autor da Natureza pôde praticar este artifício divino e infinitamente maravilhoso, porque cada porção da matéria não só é divisível ao infinito, como reconheceram os antigos, como ainda está subdividida atualmente sem fim, cada parte em partes, das quais cada uma tem algum movimento próprio; de outro modo seria impossível que cada porção da matéria pudesse expressar todo o universo. (...) Assim, vemos que cada corpo vivo tem uma Enteléquia dominante que no Animal é a Alma; mas os membros 
deste corpo vivo estão plenos de outros viventes, plantas, animais, cada um dos quais tem ainda sua Enteléquia ou Alma dominante. (LEIBNIZ, 2004, p. I43-I44)

A hierarquia entre as mônadas ou substâncias nos revela então uma distinção sutil, não tão explícita, mas ainda assim extremamente marcada, no texto leibniziano. As substâncias individuais, presentes sobretudo no Discurso, parecem se complexificar e ganhar distinções que lhe enriquecem as definições sem exatamente modificar sua estrutura central. Todas as mônadas são, assim como as substâncias então descritas, dotadas de apetite e percepção e adequadas a um plano harmônico de relações mútuas que faz mesmo a menor parcela da matéria exprimir a criação em sua totalidade, mesmo que confusamente e de maneira apenas plenamente visível a Deus; por sua vez, o conceito de forma substancial - então praticamente sinônimo ao de substância simples - passa a descrever um fenômeno mais específico, a saber, o da alma dominante que reúne em seu corpo uma infinidade de mônadas. Antes de uma mudança conceitual explícita, temos, me parece, um enriquecimento conceitual desenvolvido a partir de um aprofundamento investigativo e maturação intelectual no curso de quase três décadas. Nada nos autoriza a chamar este enriquecimento de progresso, é verdade, mas parece válido afirmar que o mundo em Leibniz atinge níveis extremamente mais complexos em seus últimos trabalhos do que poderia se depreender em seu texto de i686; para dar conta dessa complexidade, surgem as mônadas e suas distinções.

\section{CONCLUSÃO: A HARMONIA E SUA AMPLITUDE}

A respeito destas outras questões que envolvem as criaturas, em especial da união entre corpo e alma e da liberdade e espontaneidade das mônadas, 
é também muito notável uma passagem central do Sistema novo. Ali, Leibniz retoma o tema da criação das substâncias, revelando não apenas sua independência e incorruptibilidade, mas a harmonia que relaciona todo o projeto divino e à união entre corpo e alma, apontando para a necessidade de que estas tenham sido criadas

(...) de um modo tal que tudo nela surge de sua própria natureza, por uma perfeita espontaneidade em relação a ela mesma e, entretanto, em perfeita conformidade com as coisas fora dela. (...) É essa relação mútua, regrada por antecipação em cada substância do universo, que produz isso que nós chamamos de sua comunicação e que sozinha constitui a união da alma e do corpo. (LEIBNIZ, 2002, p. 27)

Percebemos, com essa passagem, a relação comunicativa entre a alma e o corpo, que também se relaciona em perfeita sintonia com o mundo ao qual se insere, i.e., se a alma se desdobra de acordo com seus desígnios individuais, independentes, exceto de Deus, e não obstante se inserem em um mundo repleto de outras mônadas individuais e divinamente criadas, suas percepções devem ser não apenas intuições ou tomadas de consciência individuais, mas expressões deste universo perfeitamente ordenado; é assim, afinal, "de algum modo e por certo tempo, segundo a relação dos outros corpos com o seu, que a alma exprime o estado do universo" (LEIBNIZ, 2004, p. 7o). Assim, percebemos, também, a conexão entre a liberdade e a harmonia lógica da criação ${ }^{7}$, onde começamos nossas

7 Um dos aspectos que mais clarificam esta harmonia, e do qual infelizmente não pudemos tratar devido ao diminuto espaço deste artigo, é o conceito de compossibilidade das substâncias: "Substâncias que são incompatíveis entre si, isto é, que não podem ser criadas conjuntamente, fazendo parte de um mesmo mundo, são batizadas por Leibniz de incompossíveis. Duas substâncias são, então, incompossíveis, nos termos leibnizianos, na medida em que elas se impedem mutuamente de existir, sendo compossíveis quando o contrário se dá" (MARQUES, 2006, p i49); em resumo, uma espécie de exigência lógica de não-contradição aos possíveis e contingentes, cuja razão de ser é a própria urgência à alteridade no sistema leibniziano. 
indagações. Afinal, Leibniz não identifica a liberdade das criaturas meramente na afirmação de que "nós somos perfeitamente independentes no que diz respeito à influência de todas as outras criaturas" (LEIBNIZ, 2002, p. I38), mas na "harmonia preestabelecida" (LEIBNIZ, 2004, p. I46, grifo do autor) por Deus e, por sua vez, na soberana inteligência deste, que segue os desígnios de sua vontade e também de seu entendimento. A liberdade e a espontaneidade em Leibniz, tanto de Deus quanto das criaturas, são algo como uma tomada de consciência e autodeterminação. "Verificamos por aí como se encontra liberdade no Autor do mundo, embora faça tudo determinadamente, porque opera conforme o princípio da sabedoria ou perfeição" (LEIBNIZ, I974, p. 395, grifo nosso); afınal, constitui na "suprema liberdade [de Deus] agir com perfeição segundo a razão soberana” (LEIBNIZ, 2004, p. 7), entre as necessidades logicamente perfeitas da metafísica e as opções moralmente perfeitas da realidade física.

O que nos remete, por fim, ao tema da Cidade de Deus, que, apesar de trazer poucos elementos adicionais, costuma ser o tema final dos textos de Leibniz. E é no mínimo extremamente propício que o autor use desta alegoria, que retrata Deus como o supremo e benevolente monarca do reino perfeito por ele criado, uma vez que, "em virtude da ordem perfeita estabelecida no universo, tudo está feito do melhor modo possível, tanto para o bem geral como também para o maior bem particular daqueles que estão persuadidos e contentes com o divino governo" (LEIBNIZ, 2004, p. I63); a "harmonia entre o reino Físico da Natureza e o reino Moral da Graça” (LEIBNIZ, 2004, p. I48) une toda a criação em um plano lógico e moralmente perfeito, necessário em suas leis, espontâneo em sua existência e perfeito em sua totalidade.

Notamos, desse modo, o rigor lógico e moral que permeia todo o pensamento de Leibniz e o sistema por ele estabelecido, e podemos enfim 
afirmar que o corpus leibniziano compõe um denso e rico sistema metafísico, marcado por toda sua diversidade conceitual. Leibniz e sua vasta obra devem ser tomados, enfim, como pensamento vivo e em constante movimento: de um lado, com temas recorrentes e proximidades indiscutíveis; de outro, com algumas divergências e conceitos um tanto polissêmicos que, não obstante, nunca fogem de uma temática central e uma teia bem ordenada. O pensamento leibniziano pode ser tomado de maneira sistemática desde que não se restrinja, assim, a uma tentativa de construção de um edifício estanque, e, sim, de um mapa conceitual com alguns marcos centrais e múltiplas vias de conexão. Abordado dessa forma, o trabalho leibniziano se revela (citando seu notório exemplo acerca da expressividade das substâncias) como que "um mundo completo", sua obra podendo ser "representada diversamente conforme as diferentes situações daquele que a olha" (LEIBNIZ, 2004, p. I8). 


\section{REFERÊNCIAS}

GOLDSCHMIDT, V. A religião de Platão. Trad. Ieda e Oswaldo Porchat Pereira. 2. ed. São Paulo: Difusão Europeia do Livro, I970.

LEIBNIZ, G: Discurso da metafísica e outros textos. Trad. Marilena Chauí. São Paulo: Martins Fontes, 2004.

. Novos ensaios sobre o entendimento humano. Trad. Luiz João Baraúna. 6. ed. São Paulo: Editora Nova Cultural, 1996.

. Sistema novo da natureza e da comunicação das substâncias e outros textos. Trad.

Edgar Marques. Belo Horizonte: Editora UFMG, 2002.

. Da origem primeira das coisas. In: NEWTON, I.; LEIBNIZ, G. Os pensadores:

Newton, Leibniz. Trad. Carlos Lopes de Mattos. São Paulo: Abril S.A. Cultural e Industrial, I974.

MARQUES, E: As origens da incompossibilidade em Leibniz. Cadernos de história e filosofia da ciência, Campinas, v. I6, n. I, p. I45-162, 2006.

SILVA, F: Universalidade e simbolização em Leibniz. Cadernos Espinosanos, São Paulo, v. $\mathrm{XV}, \mathrm{p} .4 \mathrm{I}-58,2006$. 